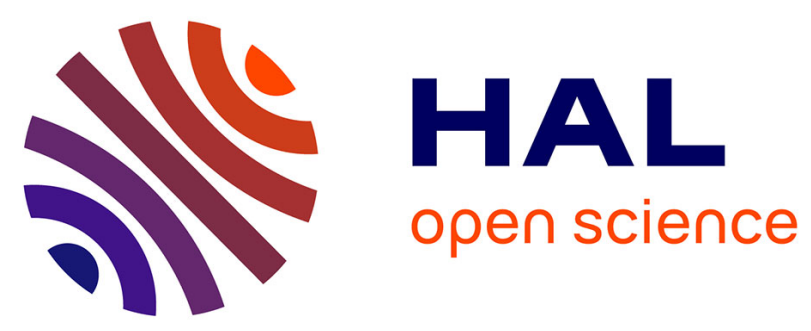

\title{
Visually- and motor-based knowledge of letters: evidence from a pure alexic patient
}

Paolo Bartolomeo, Anne-Catherine Bachoud-Lévi, Sylvie Chokron, Jean-Denis Degos

\section{- To cite this version:}

Paolo Bartolomeo, Anne-Catherine Bachoud-Lévi, Sylvie Chokron, Jean-Denis Degos. Visually- and motor-based knowledge of letters: evidence from a pure alexic patient: Visually- and motor-based knowledge of letters. Neuropsychologia, 2002, 40 (8), pp.1363-71. 10.1016/S0028-3932(01)00209-3 . inserm-00090736

\section{HAL Id: inserm-00090736 https://www.hal.inserm.fr/inserm-00090736}

Submitted on 1 Sep 2006

HAL is a multi-disciplinary open access archive for the deposit and dissemination of scientific research documents, whether they are published or not. The documents may come from teaching and research institutions in France or abroad, or from public or private research centers.
L'archive ouverte pluridisciplinaire HAL, est destinée au dépôt et à la diffusion de documents scientifiques de niveau recherche, publiés ou non, émanant des établissements d'enseignement et de recherche français ou étrangers, des laboratoires publics ou privés. 


\title{
Visually- and motor-based knowledge of letters:
}

\section{evidence from a pure alexic patient}

\author{
PAOLO BARTOLOMEO ${ }^{1,2}$ \\ ANNE-CATHERINE BACHOUD-LÉVI ${ }^{2,3}$ \\ SYLVIE CHOKRON ${ }^{4,5}$ \\ JEAN-DENIS DEGOS ${ }^{2}$ \\ ${ }^{1}$ INSERM Unit 324, Centre Paul Broca, 2ter rue d'Alésia, F-75014 Paris, France \\ ${ }^{2}$ Neuroscience Department, Hôpital Henri-Mondor, Créteil, France \\ ${ }^{3}$ LSCP, EHESS, CNRS, Paris, France \\ ${ }^{4}$ Laboratoire de Psychologie Expérimentale, CNRS UMR 5105, Grenoble, France \\ ${ }^{5}$ Fondation Ophtalmologique Rothschild, Paris, France \\ In the days following the submission of this article, Professor Jean-Denis Degos died after a street accident. \\ His co-authors wish to express their profound sorrow at this loss. His human sympathy, thoughtful \\ appreciation of culture, and motivating enthusiasm will be deeply missed.
}

\begin{tabular}{|ll|}
\hline Correspondence to: & Paolo Bartolomeo \\
& INSERM Unit 324 \\
& Centre Paul Broca \\
& 2ter rue d'Alésia \\
& F-75014 Paris, France \\
& $+33(0) 140789210$ \\
Telephone: & $+33(0) 145896848$ or $(0) 145807293$ \\
Facsimile: & paolo@broca.inserm.fr \\
e-mail: &
\end{tabular}

Running head: $\quad$ Visually- and motor-based knowledge of letters

Shortened title: $\quad$ Knowledge of letter form 


\section{Abstract}

We describe a patient, VSB, whose reading was impaired as a consequence of a left temporal-parietal lesion, whereas writing was relatively preserved. At variance with other pure alexic patients described in the literature, VSB claimed to have become unable to mentally visualise letters and words. Indeed, his performance on a series of tests tapping visual mental imagery for orthographic material was severely impaired. However, performance on the same tests was dramatically ameliorated by allowing VSB to trace each item with his finger. Visual mental imagery for non-orthographic items was comparatively spared. The pattern of dissociation shown by VSB between impaired visual mental imagery and relatively preserved motor-based knowledge for orthographic material lends support to the view that separate codes, respectively based on visual appearance and on motor engrams, may be used to access knowledge of the visual form of letters and words.

Keywords: Pure alexia, Visual mental imagery 


\section{Introduction}

Visually presented letters and words constitute a particular class of visual objects for literate people. Left posterior brain damage can disrupt their processing in the relative absence of other deficits (and notably, with preserved writing), a disorder known as pure alexia. Demanding visual tests can uncover subtle abnormalities for non-orthographic material in pure alexic patients [9, 24, 27]. However, the reading disorder is typically the major complaint of these patients, and constitutes their main difficulty in everyday life. Patients with pure alexia can occasionally be unable to read even a single letter [20]. More often, they can identify letters, albeit with reduced speed and accuracy, and read words slowly and one letter at a time (letter-by-letter reading). As a consequence, they show a word length effect in oral word reading. Pure alexia might result from different functional deficits [48], but an impairment of visual letter identification has been repeatedly underlined $[1,4,11,47]$ (see [10] for review).

Does this difficulty in identifying visually presented letters reflect an impaired mental representation of the letters, or are these representations intact, as suggested by patients' preserved ability to write? To assess the integrity and the availability of visual representations, one may ask subjects to conjure up a mental image of the relevant object, and record their performance on a variety of tasks requiring processing of these visual mental images [see 38]. Unfortunately, visual knowledge of letters has rarely been explored in pure alexia. In those studies in which such an assessment has been made, patients were able to perform tasks requiring visual mental imagery of letters. For example, KQu [31], a pure alexic patient with impaired imagery for the form and colour of objects, performed in the normal range when asked to count the corners of upper-case letters, whose names were auditorily presented. Patient SP [47], who made errors on visual identification of words and single letters, could accurately describe the form of letters from memory, or answer to specific questions about the structural characteristics of letters. Similarly, patient CK [8], who was unable to identify letters and words on visual presentation, could nevertheless perform at ceiling several difficult tasks requiring the processing of visual mental images of orthographic material. Madame D, a pure alexic patient whose residual reading capacities were disrupted by a second, right 
hemisphere lesion [5], showed a similar pattern of dissociation between severely impaired visual identification of letters, words and digits, and intact visual mental imagery for these same visual entities [3].

In this latter study, it was suggested that mental imagery for letters might have a different status from visual knowledge of object form, faces and colours [see also 32], because letter imagery seems to rely on subtler spatial constraints as compared with these other visual items. Moreover, knowledge of letter form might be used for the motor act of writing. In support of this notion, an impairment of letter imagery has been described in agraphic patients with parietal lesions [16, 28, 42], rather than in pure alexic patients. Indeed, as Goldenberg [32] pointed out, when asked questions about the physical appearance of letters one may find oneself responding either by mentally reading or by mentally writing the relevant letter. Although the latter may be more common, Goldenberg [32] recognized the possibility that some alexic patients might show impaired letter imagery, provided that these patients rely primarily on mental reading to solve the letter imagery tasks.

Here we confirm this prediction by describing the case of an alexic patient with preserved writing who claimed to have lost the visual mental images of letters, and indeed showed severely impaired performance on tests tapping visual mental imagery for orthographic material. Interestingly, his performance was dramatically ameliorated when he was allowed to trace the contour of these items with his fingers. This pattern of performance suggests that at least two codes, one visually-based and the other motor-based, may be used to solve tasks requiring visual mental imagery of letters.

\section{Case report}

VSB, a 62-year-old cardiologist, was admitted to hospital because of a generalized convulsive crisis. A cerebral haematoma was discovered and surgically evacuated, leaving a residual lesion in the left temporal and parietal lobes (Fig. 1). After the acute phase of the disease, the patient was initially severely anomic and produced occasional phonemic paraphasias; these aphasic symptoms gradually improved. At the time of testing, VSB had a mild impairment of word finding leading to occasional semantic paraphasias or 
circumlocutions. Writing was preserved, with occasional spelling errors (Fig. 2). VSB never showed problems in recognizing familiar faces.

Fig. 1 and 2 about here

He performed either at ceiling or in the normal range on all the subtests of the VOSP [56] (Table 1), thus showing normal visual processing in the domains probed by this battery.

Table 1 about here

VSB claimed to have normal colour vision. He could name with reasonable accuracy colour patches. He scored $100 \%$ correct on the Ishiara test for colour blindness [35] and proposed a reasonable order for the colour patches of the Farnsworth dichotomous test [25], producing a single error. The obtained order was as follows: $1,2,3,4,5,6,7,15,14,13,12,11,10,9,8$.

\section{Reading tests}

Word reading. At the time of testing, VSB's only complaint was his reading disorder. We presented him with a list of 100 words, consisting of groups of 20 words of 4, 5, 6, 7 and 8 letters in length, printed in lower case on a paper strip. Half of the stimuli were high-frequency words ( $>50$ per million from the Brulex database for French word counts [15]), half were low-frequency words ( $<13$ per million). Accuracy and reading time were recorded manually by the examiner, who started a stopwatch upon stimulus presentation and stopped it when the response was complete. VSB read slowly and letter by letter, with frequent hesitations. He read 84 out of 100 words correctly. A word length effect was present (Fig. 3), with reading time increasing by about $3.7 \mathrm{sec}$ for the $5^{\text {th }}$ and $6^{\text {th }}$ letter. The word length effect was less evident for longer words, perhaps because it was concealed by guessing. Reading time was also influenced by lexical frequency; high-frequency words evoked faster responses $(12.9 \mathrm{sec})$ than low-frequency words 
$(18.4 \mathrm{sec}), \mathrm{t}(82)=2.14, \mathrm{p}<0.05$. VSB thus showed the common reading profile of pure alexic patients [see $10]$.

Fig. 3 about here

Letter and digit reading. VSB was asked to read lower- and uppercase letters and digits presented in isolation on a paper sheet, printed in Times New Roman 48. He was slow and hesitating, taking 2-3 seconds per item, but was eventually able to read 25/26 lowercase letters (error: $y \rightarrow$ ' $x$ '), 24/26 uppercase letters (errors: $P \rightarrow$ 'R', $Q \rightarrow$ 'S'), and the totality of the digits.

\section{Imagery of orthographic material}

Unless otherwise mentioned, VSB's performance in imagery tests was contrasted with that of six righthanded individuals without brain damage, aged 48-77 years (mean, 64.00; SD, 13.33).

Uppercase letter imagery. We asked subjects to state from memory whether uppercase letters named by the examiner contained any curved lines [14]. All the letters of the French alphabet were presented. VSB performed this task twice, on two separate occasions (Table 2).

Table 2 about here

On both occasions, his performance did not significantly differ from chance, $\chi^{2}(1) \leq 2.93$. For example, he said that the letter $S$ has only straight lines. On a third occasion, we allowed him to trace the contour of the letter with his finger on the table. This time, his responses were faultless (26/26 correct), with only slight hesitation for $U$ and $K$.

Mental letter construction. Subjects were required to identify uppercase letters which they had to mentally construct following oral instructions. We developed a French version of this test devised by 
Morris Moscovitch [8]. A question was asked for every letter of the alphabet (e.g., "Take the letter V, turn it upside down. Put a horizontal line through the middle of it. What is the result?"). VSB claimed to be unable to visualise the letters while he was trying to mentally construct them. "It's blurred, it's strange", were his comments. He hesitated before producing a frequently incorrect response. For example, when asked to imagine a $Q$, and to take away the small stroke at the bottom, he said that the result was "I". He sometimes tried to draw the items with his finger on the table in front of him, a strategy which we discouraged. Eventually, he gave only five corrects responses.

To ascertain that his defective performance on this task did not depend on a failure to understand the instructions (which were indeed complex for some of the items, see the Appendix in [8]), we asked VSB to perform the same task again, this time allowing him to follow the instructions by drawing the letters on a paper with a pencil. In this condition, his performance rose to $21 / 26(81 \%)$ correct, which is fairly satisfactory, taking into account his alexia and the controls' level of performance on the version of the task performed without visual aid (see Table 2).

Lowercase letter imagery. We invited subjects to state from memory whether lowercase letters named by the examiner contained an ascender (e.g., b, h), a descender (p, g), or neither (m, e). Again, all the letters of the alphabet were presented. VSB's performance was severely defective, because he gave only five correct responses. Also in this case we subsequently allowed the patient to use his finger to draw on the table the letters. Again, this strategy dramatically improved his performance (see Table 2). While still defective as contrasted to controls' performance, the strategy of tracing the letters led to a statistically significant improvement in VSB's performance, $\chi^{2}(1)=7.99$ (continuity-corrected), $\mathrm{p}<0.005$.

Word imagery. A list of 40 words was prepared. Ten contained one or more letters with an ascender (e.g., b, h), ten contained one or more letters with a descender (p, g), ten contained letters with both ascenders and descenders, and ten contained letters with neither. Subjects listened to the words one at a time, and had to state from memory whether the word contained vertically long letters or not, and, if so, whether the letter(s) crossed the higher or the lower boundary of the line [57]. VSB performed this task 
twice, on separate test sessions. The first time he scored 55\% correct. The second time was during a relatively late test session, and, though still claiming of being unable to visualise the words in his mind's eye, VSB often could not help tracing the words with his finger on the table. Despite this strategy (which we were not able to prevent), his performance remained defective (see Table 2). Most of his errors on this session $(n=7)$ concerned words that crossed both the inferior and the superior borders, and presumably arose because VSB produced an 'ascender' or 'descender' response as soon as he encountered one such letter while tracing the words, without completing the tracing to see whether a letter from another category was present.

\section{Imagery of non-orthographic material}

Although the present study is primarily concerned with imagery for orthographic material, we tested VSB on a variety of tasks tapping visual mental imagery abilities for object form, object colour, faces, and spatial relationships. Neuropsychological evidence suggests that each of these imagery domains may be affected independently of the others [32]. The patterns of co-occurrence of different imagery and perceptual deficits may ultimately shed light on the mechanisms of mental imagery abilities and on their relationships with perceptual processes $[3,23]$. VSB claimed to be able to visually imagine nonorthographic items, and indeed showed normal or near-normal performance in the experimental tasks involving these items.

Table 3 about here

Object form. Table 3 shows the performance of VSB and the control subjects on imagery tests for object form. Subjects were asked oral questions concerning the visual appearance of objects and animals. Subjects had to state from memory whether the object corresponding to the name spoken by the examiner (e.g., a mug) was higher than it is wide or wider than it is high [see 41]. Another list of pairs of object names was presented, the subjects having this time to state which object had a larger size [see 53]. In a 
third task, animal names were orally presented (e.g., deer), subjects having to judge from memory whether each animal is larger or smaller than a goat [see 41]. Finally, pairs of names referring to morphologically similar objects (e.g., nail/screw) were presented orally, and subjects had to state which visual detail was typically different between the objects referred to by the members of each pair [see 18]. VSB performed this task twice on separate occasions. He performed all these task at ceiling or in the normal range, except for the 'discriminating detail' test, in which he made one more mistake than the worst performance of controls. However, at a subsequent retest VSB's performance on this task was found normal.

Colour. Fifteen pairs of items were proposed verbally by the examiner [see 19]. Each pair was composed of objects of the same colour with a different hue (e.g., spinach/lettuce). Subjects were asked to say which of the items within a pair was lighter in colour. Results of colour imagery tests are reported in Table 4. VSB made one more error than the worst performance of 18 normal controls (mean age 62.88, SD 10.92). This result raises the possibility that imagery for colours, while phenomenally possible, was not perfectly intact in VSB. It must be noted, however, that most items in the mental hue discrimination tests concerned fruit or vegetables, items with which VSB was not particularly familiar. To further explore VSB's imagery for colours, we asked him to say the typical colour of 20 orally presented items (e.g., elephant, fir, carrot). VSB's performance in this task was errorless. In a further test, we presented him with plates containing a correctly coloured item among five incorrectly coloured copies (e.g., a yellow banana among green, blue, red, pink and violet ones). VSB performed this task in the range of five controls (mean age, 53.60 years; $\mathrm{SD}, 20.82)$.

Table 4 about here

Faces. We asked subjects questions about the overall shape of the face (round, oval, etc.), the shape of the nose (thin/large), and the shape of the lips (thin/fleshy) of famous faces (e.g., "Were Marilyn Monroe's lips rather thin or fleshy?"). VSB performed this task in the normal range (see Table 5). 
Table 5 about here

Spatial relationships. VSB was perfectly oriented in space, and capable of getting to the test rooms at the Neurological Department of the Henri-Mondor Hospital on his own, after following a rather complex route. He claimed to be able to mentally imagine routes and places, of which he produced plausible descriptions. To collect evidence relevant to this issue, we asked VSB and ten control subjects (mean age 58.90, SD 6.84) to perform a task inspired by Finke and Pinker [26]. Subjects saw a pattern composed of either 3 or 4 dots randomly placed on a horizontal A4 sheet. In a 'perceptual' condition, a central arrow was presented on the sheet, pointing either toward one of the dots, or toward an empty space between dots. The subjects' task was to determine whether the arrow pointed to one of the dots or not. For half of the items, the arrow pointed leftward, for the other half it pointed rightward. In an 'imagery' condition, the stimulus and procedure were the same, except that subjects saw the arrow (printed on a different sheet) only after the dots had disappeared. In practice, a sheet containing only the dots was presented for $5 \mathrm{sec}$, followed by a blank sheet and by a sheet containing only the arrow. Subjects had thus to imagine the spatial position of the dots in order to perform the task. VSB performance (shown in Table 5) was faultless in the perceptual condition. In the imagery condition, he made ten errors, five for left- and five for right-directed arrows. This result was in the lower range of controls' performance.

\section{Discussion}

We described the case of VSB, a pure alexic patient with impaired knowledge of the visual appearance of letters and words. His knowledge of visual aspects of other items was comparatively preserved ${ }^{1}$, as was

\footnotetext{
${ }^{1}$ As reported in the Results section, VSB's performance was occasionally slightly impaired on tasks exploring shape and colour imagery. Such impairments would accord well with the literature on imagery in
} 
mental imagery for spatial relationships. The pattern of dissociation shown by VSB between impaired visual mental imagery and relatively preserved motor-based knowledge for orthographic material suggests that separate codes, respectively based on visual appearance and on motor engrams, may be used to access knowledge of the visual form of letters and words.

To the best of our knowledge, this is the first observation of a relatively selective deficit of visual mental imagery for orthographic material in a patient with alexia without agraphia. The previously described cases of letter imagery deficits $[16,28,42]$ had a concomitant writing disorder. Although our patient's lesion extended to the parietal lobe, it apparently did not affect his ability to trace well-formed letters or words.

Crary and Heilman [16] reported the case of a patient who, after sustaining a high left parietal lesion, showed severely impaired performance in letter writing and concomitant, although apparently less severe, deficits of spatial imagery and of visual mental imagery for letters. These authors concluded that a 'graphemic area' in the parietal lobe contains knowledge of the physical aspects of letters and is responsible for transcoding these features into the motor act of writing (see also [50]). Déjerine [20] proposed that the left angular gyrus contains the 'optical images of letters', whose loss is one cause of agraphia. Our observation, that a deficit of letter imagery may be present in the absence of agraphia, and that motor rehearsal may help circumvent this deficit, suggests that separate codes may be used for representing the visual appearance and the motor programs associated with letters. Within this framework, it is conceivable that concomitant damage to these motor representations, as may have been the case for the Crary and Heilman patient, may aggravate a deficit of visual imagery for letters. Consistent with these notions, visual imagery for letters may be normal in agraphic patients with parietal damage [see, e.g., patient BT in Ref. 28].

patients with left temporal lesions [2]. However, VSB's massive deficit of letter and word imagery was clearly disproportionate to these putative impairments. 
If, as suggested by the present results, different abilities underlie the knowledge of the visual aspect of letters and the spatio-motor programs used to trace them ${ }^{2}$, then one might expect that agraphic patients with selective deficits for the spatio-motor aspects of letters might use their spared visual knowledge of letters to improve their writing. Indeed, a Japanese patient with apraxic dysgraphia due to thalamic damage could use his intact visual images of kanji characters to write them by building the corresponding visual letter images and subsequently copying them on the sheet [46]. Conversely, pure alexic patients may learn to use their (intact) motor representations of letters in order to facilitate reading. As already noted by Déjerine [20], a patient with pure alexia, "who can neither read nor even re-read his own writings, can nevertheless manage to do so by using an artifice that involves his muscular sense. By following with his finger the contours of the letters of by tracing them on the palm of his hand, he can manage to spell letters and words" (p. 32). These strategies may be at the basis of the use of kinaesthetic reading in rehabilitation of pure alexia [51]. A particularly impressive case of spontaneous use of kinaesthetic reading in pure alexia comes from the report of patient Schneider $^{3}$ [30] (English translation in [21]), who had a reading impairment which allowed him to (slowly) read words when presented in free vision, but not tachistoscopically. "His reading was accomplished by a series of minute head- and hand-movements - he 'wrote' with his hand what his eyes saw" [30] (p. 317 of the English translation [21]). As a matter of fact, reading, as well as visual object identification, was impossible if Schneider was prevented from adopting

${ }^{2}$ This notion leaves of course open the possibility that normal subjects may preferentially use a motorbased strategy to mentally solve problems related to the visual shape of letters $[32,40]$. Why VSB did not spontaneously do so remains an open question (note, however, that after a few testing sessions he did began to spontaneously trace letters and words in the air or on the table, when questioned about their visual form).

${ }^{3}$ A reviewer of the present article pointed out that the validity of this patient's symptoms has been doubted. As Teuber formulated in his obituary [55] to Kurt Goldstein, "Schneider ... to some of us seemed like the platonic idea of a brain-injured patient than a patient himself' (p. 306). 
this strategy (of which he was totally unaware) by impeding head or body movements. Although unfortunately there is no mention of visual imagery for letters in the Gelb and Goldstein report, Schneider claimed to have lost the ability of forming any visual image. Sirigu and Duhamel [54] recently reported on a patient (JB), who, after lesions to both temporal poles due to herpes simplex encephalitis, showed a pattern of performance for letter imagery similar to that of VSB. JB, who was unable to visualize objects, colours and faces (without corresponding deficits in perception), performed at chance when comparing upper-case letters on the basis of their imagined lower-case appearance, unless micro-movements of the fingers were allowed, which markedly improved his performance. In a similar way, he could solve tasks involving mental rotation of hands only when the task conditions encouraged covert motor processing. According to the leading cognitive model of visual mental imagery [22, 39], visual mental images are produced by a retro-activation [17] of early visual cortices by more anterior areas, where semantic knowledge is stored. In the case of a perceptual deficit, a corresponding mental imagery deficit should cooccur, because "no other cortices, and certainly no other higher order, integrative cortices, are capable of supporting the recall of the perceptually impaired feature" [17, p. 33]. Recent neuropsychological evidence of double dissociations between perceptual and imagery abilities [3, 6-8, 12, 13, 36, 49] (see [33] and [2] for recent reviews) urges for a revision of this hypothesis, because the integrity of occipital visual areas seems far from being crucial for imagery abilities ${ }^{4}$. Our present results concur with other abundant evidence in suggesting that damage to downstream visual areas located in the temporal lobes is, instead, both necessary and sufficient to produce visual imagery deficits [13, 19, 43, 49, 52, 54]. In the domain of pure alexia, we see as particularly suggestive the contrast between the patterns of performance of Madame D [3], whose lesions affected BA 18, 19 and 37, and whose visual mental imagery for letters and words was entirely spared (despite her profound alexia), and of VSB, whose lesion extended much more anteriorly into the left temporal lobe, as well as into the parietal lobe, and who showed severely impaired

\footnotetext{
${ }^{4}$ Also, several neuroimaging studies [reviewed in 44] found no evidence of an increased activity in early visual cortices during visual mental imagery.
} 
imagery for the visual aspects of orthographic material. Structures including the infero-temporal cortex, the mesial temporo-limbic regions and perhaps the temporal pole might be critical for processing of knowledge based upon visual information [29, 45]. Damage to domain-specific regions [37] or circuits [34] in the ventral temporal lobe might thus contribute to the occurring of selective deficits of visually-based knowledge. 


\section{References}

1. Arguin, M and Bub, DN. Single-character processing in a case of pure alexia. Neuropsychologia $1993 ; 31: 435-58$.

2. Bartolomeo, P. The relationship between visual perception and visual mental imagery: a reappraisal of the neuropsychological evidence. Cortex, under review.

3. Bartolomeo, P, Bachoud-Lévi, AC, de Gelder, B, Denes, G, Dalla Barba, G, Brugières, P and Degos, JD. Multiple-domain dissociation between impaired visual perception and preserved mental imagery in a patient with bilateral extrastriate lesions. Neuropsychologia 1998;36:239-49.

4. Bartolomeo, P, Bachoud-Lévi, AC and Degos, JD. A hidden letter identification deficit in a pure alexic patient. Poster presented at the Fourteenth European Workshop on Cognitive Neuropsychology, Bressanone, Italy, January 1996.

5. Bartolomeo, P, Bachoud-Lévi, AC, Degos, JD and Boller, F. Disruption of residual reading capacity in a pure alexic patient after a mirror-image right hemispheric lesion. Neurology 1998;50:286-8.

6. Bartolomeo, P, Bachoud-Lévi, AC and Denes, G. Preserved imagery for colours in a patient with cerebral achromatopsia. Cortex 1997;33:369-78.

7. Basso, A, Bisiach, E and Luzzatti, C. Loss of mental imagery: a case study. Neuropsychologia $1980 ; 18: 435-42$.

8. Behrmann, M, Moscovitch, M and Winocur, G. Intact visual imagery and impaired visual perception in a patient with visual agnosia. Journal of Experimental Psychology: Human Perception and Performance 1994;20:1068-87.

9. Behrmann, M, Nelson, J and Sekuler, EB. Visual complexity in letter-by-letter reading: "pure" alexia is not pure. Neuropsychologia 1998;36:1115-32.

10. Behrmann, M, Plaut, DC and Nelson, J. A literature review and new data supporting an interactive account of letter-by-letter reading. Cognitive Neuropsychology 1998;15:7-51. 
11. Behrmann, M and Shallice, T. Pure alexia: A nonspatial visual disorder affecting letter activation. Cognitive Neuropsychology 1995;12:409-54.

12. Behrmann, M, Winocur, G and Moscovitch, M. Dissociation between mental imagery and object recognition in a brain-damaged patient. Nature 1992;359:636-7.

13. Chatterjee, A and Southwood, MH. Cortical blindness and visual imagery. Neurology 1995;45:218995.

14. Coltheart, M, Hull, E and Slater, D. Sex differences in imagery and reading. Nature 1975;253:434-40.

15. Content, A, Mousty, P and Radeau, M. Brulex, une base de données lexicales informatisée pour le français écrit et parlé. L'Année Psychologique 1990;90:551-66.

16. Crary, $\mathrm{M}$ and Heilman, K. Letter imagery deficits in a case of pure apraxic agraphia. Brain and Language 1988;34:147-56.

17. Damasio, A. Time-locked multiregional retroactivation: A system-level proposal for the neuronal substrates of recall and recognition. Cognition 1989;33:25-62.

18. De Renzi, E and Lucchelli, F. The fuzzy boundaries of apperceptive agnosia. Cortex 1993;29:187-215.

19. De Vreese, LP. Two systems for colour-naming defects: Verbal disconnection vs colour imagery disorder. Neuropsychologia 1991;29:1-18.

20. Déjerine, MJ. Contribution à l'étude anatomo-pathologique et clinique des différentes variétés de cécité verbale [Contribution to the pathological and clinical investigation of different varieties of word blindness]. Mémoires de la Société de Biologie 1892;4:61-90.

21. Ellis, WD, editor. A source book of Gestalt psychology. New York: The Humanities Press, 1950.

22. Farah, MJ. The neurological basis of mental imagery: A componential analysis. Cognition $1984 ; 18: 245-72$.

23. Farah, MJ. Is visual imagery really visual? Overlooked evidence from neuropsychology. [Review]. Psychological Review 1988;95:307-17. 
24. Farah, MJ and Wallace, MA. Pure alexia as a visual impairment: A reconsideration. Cognitive Neuropsychology 1991;8:313-34.

25. Farnsworth, D. Farnsworth dichotomous test for colour-blindness - panel D-15. New York: The Psychological Corporation, 1947.

26. Finke, RA and Pinker, S. Spontaneous imagery scanning in mental extrapolation. Journal of Experimental Psychology: Learning, Memory and Cognition 1982;8:142-7.

27. Friedman, RB and Alexander, MP. Pictures, images, and pure alexia: A case study. Cognitive Neuropsychology 1984;1:9-23.

28. Friedman, RB and Alexander, MP. Written spelling apraxia. Brain and Language 1989;36:503-17.

29. Gainotti, G. What the locus of brain lesion tells us about the nature of the cognitive defect underlying category-specific disorders: a review. Cortex 2000;36:539-59.

30. Gelb, A and Goldstein, K. Zur Psychologie des optischen Wahrnehmungs- und Erkennungvorganges (Psychologische Analyse hirnpathologischer Fälle auf Grund von Untersuchungen Hirnverletzer, I.). Zeitschrift für die gesammte Neurologie und Physiologie 1918;41:1-143.

31. Goldenberg, G. Loss of visual imagery and loss of visual knowledge - A case study. Neuropsychologia 1992;30:1081-99.

32. Goldenberg, G. The neural basis of mental imagery. Baillière's Clinical Neurology 1993;2:265-86.

33. Goldenberg, G. Is there a common substrate for visual recognition and visual imagery? Neurocase 1998;4:141-7.

34. Ishai, A, Ungerleider, LG, Martin, A, Schouten, JL and Haxby, JV. Distributed representation of objects in the human ventral visual pathway. Proceedings of the National Academy of Sciences of the United States of America 1999;96:9379-84.

35. Ishihara, S. Tests for colour-blindness. Tokio: Kanehara Shup, 1974.

36. Jankowiak, J, Kinsbourne, M, Shalev, RS and Bachman, DL. Preserved visual imagery and categorization in a case of associative visual agnosia. Journal of Cognitive Neuroscience 1992;4:119-31. 
37. Kanwisher, N. Domain specificity in face perception. Nature Neuroscience 2000;3:759-63.

38. Kosslyn, SM. Image and Mind. Cambridge, MA: Harvard University Press, 1980.

39. Kosslyn, SM. Image and Brain: The Resolution of the Imagery Debate. Cambridge, Mass.: The MIT Press, 1994.

40. Kosslyn, SM, Cave, CB, Provost, DA and von Gierke, SM. Sequential processes in image generation. Cognitive Psychology 1988;20:319-43.

41. Kosslyn, SM, Holtzman, JD, Farah, MJ and Gazzaniga, MS. A computational analysis of mental image generation: evidence from functional dissociations in split-brain patients. Journal of Experimental Psychology: General 1985;114:311-41.

42. Levine, DN, Mani, RB and Calvanio, R. Pure agraphia and Gerstmann's syndrome as a visuospatiallanguage dissociation: an experimental case study. Brain and Language 1988;35:172-96.

43. Luzzatti, C and Davidoff, J. Impaired retrieval of object-colour knowledge with preserved colour naming. Neuropsychologia 1994;32:933-50.

44. Mellet, E, Petit, L, Mazoyer, B, Denis, M and Tzourio, N. Reopening the mental imagery debate: lessons from functional anatomy. Neuroimage 1998;8:129-39.

45. Miceli, G, Fouch, E, Capasso, R, Shelton, JR, Tomaiuolo, F and Caramazza, A. The dissociation of color from form and function knowledge. Nature Neuroscience 2001;4:662-7.

46. Ohno, T, Bando, M, Nagura, H, Ishii, K and Yamanouchi, H. Apraxic agraphia due to thalamic infarction. Neurology 2000;54:2336-9.

47. Perri, R, Bartolomeo, P and Silveri, MC. Letter dyslexia in a letter-by-letter reader. Brain and Language 1996;53:390-407.

48. Price, CJ and Humphreys, GW. Letter-by-letter reading? Functional deficits and compensatory strategies. Cognitive Neuropsychology 1992;9:427-57.

49. Riddoch, MJ. Loss of visual imagery: A generation deficit. Cognitive Neuropsychology 1990;7:249-73. 
50. Rothi, LJ and Heilman, KM. Alexia and agraphia with spared spelling and letter recognition abilities. Brain and Language 1981;12:1-13.

51. Seki, K, Yajima, M and Sugishita, M. The efficacy of kinesthetic reading treatment for pure alexia. Neuropsychologia 1995;33:595-609.

52. Shelton, PA, Bowers, D, Duara, R and Heilman, KM. Apperceptive visual agnosia. A case study. Brain and Cognition 1994;25:1-23.

53. Sheridan, J and Humphreys, GW. A verbal-semantic category-specific recognition impairment. Cognitive Neuropsychology 1993;10:143-84.

54. Sirigu, A and Duhamel, JR. Motor and visual imagery as two complementary but neurally dissociable mental processes. Journal of Cognitive Neuroscience in press;

55. Teuber, H-L. Kurt Goldstein's role in the development of neuropsychology. Neuropsychologia $1966 ; 4: 299-310$.

56. Warrington, EK and James, M. The Visual Object and Space Perception Battery. Bury St Edmunds: Thames Valley Test Company, 1991.

57. Weber, RJ and Castleman, J. The time it takes to imagine. Perception and Psychophysics 1970;8:165-8. 
Table 1. VSB's performance on the VOSP [56].

\begin{tabular}{lcc}
\hline Subtest & VSB's score & Cut-off score \\
\hline Screening test $(\mathbf{N}=\mathbf{2 0})$ & 20 & $\geq 15$ \\
Incomplete letters $(\mathbf{N}=\mathbf{2 0})$ & 20 & $\geq 16$ \\
Silhouettes $(\mathbf{N}=\mathbf{3 0})$ & 19 & $\geq 15$ \\
Object decision $(\mathbf{N}=\mathbf{2 0})$ & 15 & $\geq 15$ \\
Progressive silhouettes $(\mathbf{N}=\mathbf{2 0})$ & 9 & $\geq 8$ \\
Dot counting $(\mathbf{N}=\mathbf{1 0})$ & 10 & $\geq 18$ \\
Position discrimination $(\mathbf{N}=\mathbf{2 0})$ & 19 & $\geq 7$ \\
Number location $(\mathbf{N}=\mathbf{1 0})$ & 10 & $\geq 6$ \\
Cube analysis $(\mathbf{N}=\mathbf{1 0})$ & 9 & \\
\hline
\end{tabular}


Table 2. Performance (number and percentage of correct responses) of VSB and controls on tests tapping mental imagery for letters and words.

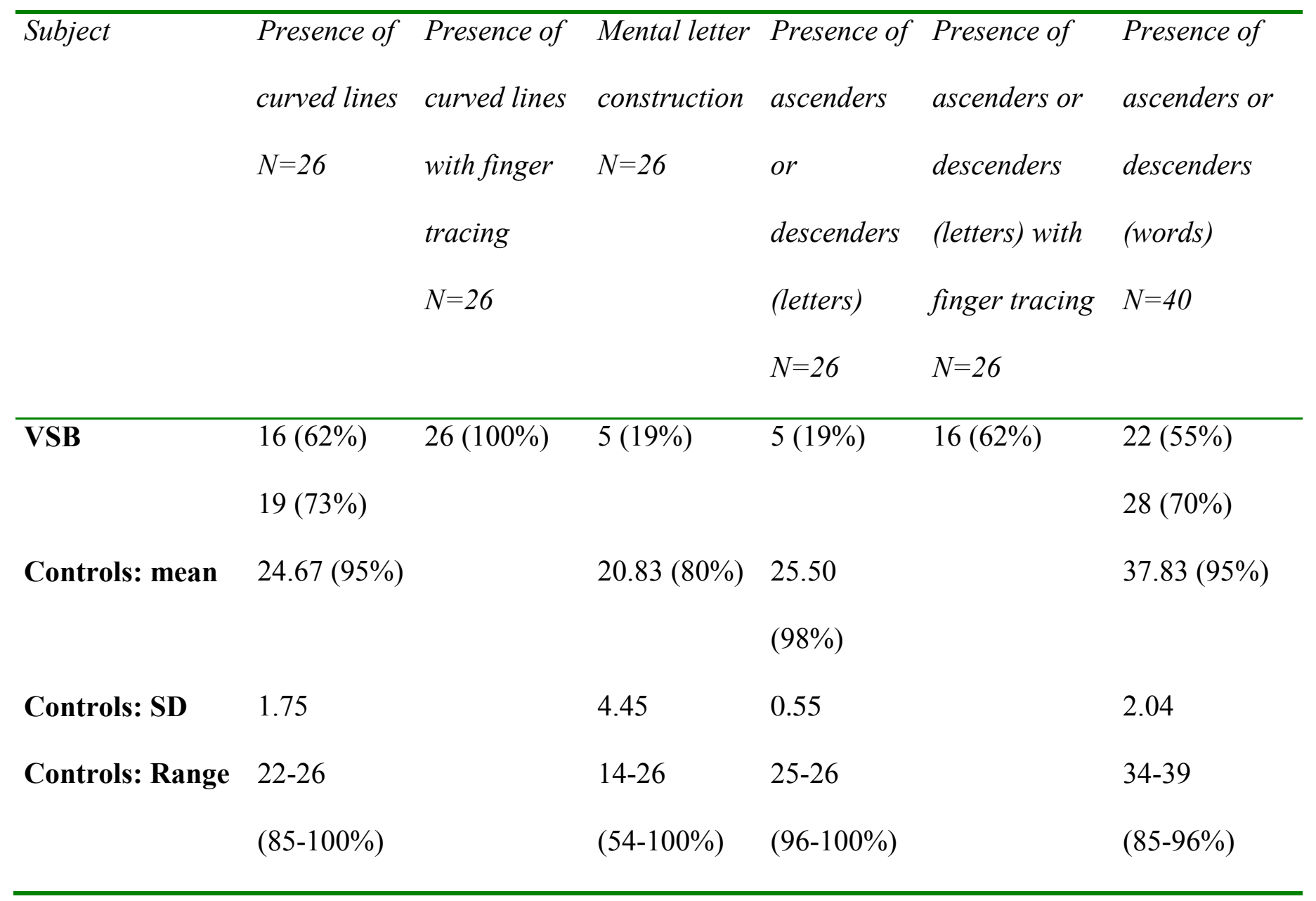


Table 3. Performance (number and percentage of correct responses) of VSB and controls on tests tapping mental imagery for object form and size.

\begin{tabular}{lllll}
\hline Subject & Object form 1 & Object form 2 & Animal size & Discriminating \\
& (high/wide) & (bigger/smaller) & $N=26$ & detail \\
& $N=26$ & $N=18$ & $N=10$ \\
\hline VSB & $25(96 \%)$ & $18(100 \%)$ & $26(100 \%)$ & $7(70 \%)$ \\
& & & & $8(80 \%)$ \\
Controls: mean & $24.00(92 \%)$ & $18.00(100 \%)$ & $25.50(98 \%)$ & $9.00(90 \%)$ \\
Controls: SD & 1.10 & 0.00 & 0.84 & 0.90 \\
Controls: Range & $23-25$ & - & $24-26$ & $8-10$ \\
& $(88-100 \%)$ & & $(92-100 \%)$ & $(80-100 \%)$ \\
\hline
\end{tabular}


Table 4. Performance (number and percentage of correct responses) of VSB and controls on tests tapping mental imagery for colours.

\begin{tabular}{llll}
\hline Subject & Mental hue & Typical colour & Correctly coloured \\
& discrimination & $N=20$ & alternative \\
& $N=15$ & $N=20$ \\
\hline VSB & $10(67 \%)$ & $20(100 \%)$ & $18(90 \%)$ \\
Controls: mean & $13.44(89 \%)$ & $18.00(90 \%)$ \\
Controls: SD & 1.34 & 1.58 \\
Controls: Range & $11-15$ & $16-20$ \\
& $(73-93 \%)$ & $(80 \%-100 \%)$ \\
\hline
\end{tabular}


Table 5. Performance (number and percentage of correct responses) of VSB and controls on tests tapping mental imagery of familiar faces and perception and imagery of spatial relationships.

\begin{tabular}{llll}
\hline Subject & Familiar faces & Spatial relationships: & Spatial relationships: \\
& $N=18$ & perception & imagery \\
& & $N=32$ & $N=32$ \\
\hline VSB & $15(83 \%)$ & $32(100 \%)$ & $22(69 \%)$ \\
Controls: mean & $15.00(83 \%)$ & $32(100 \%)$ & $26.90(84 \%)$ \\
Controls: SD & 1.10 & 0.00 & 3.07 \\
Controls: Range & $14-16$ & - & $22-32$ \\
& $(78-89 \%)$ & & $(69-100 \%)$ \\
\hline
\end{tabular}




\section{Figure legends}

Fig. 1. FLAIR MRI axial scans showing a temporal-parietal lesion in the left hemisphere.

Fig. 2. Writing on dictation of the following items: 'amour' (love), 'animal', 'cerveau' (brain), 'activité' (activity, note the addition of a final e), 'ciel' (sky), 'boite' (box), 'homme' (man, note the omission of the 'o'), 'un gars' (a boy, the ' $\mathrm{n}$ ' is replaced by a ' $\mathrm{m}$ '), 'les oiseaux chantent dans les buissons' (the birds are singing in the bushes).

Fig. 3. Mean reading time for correctly read words of different length. 
Figure 1
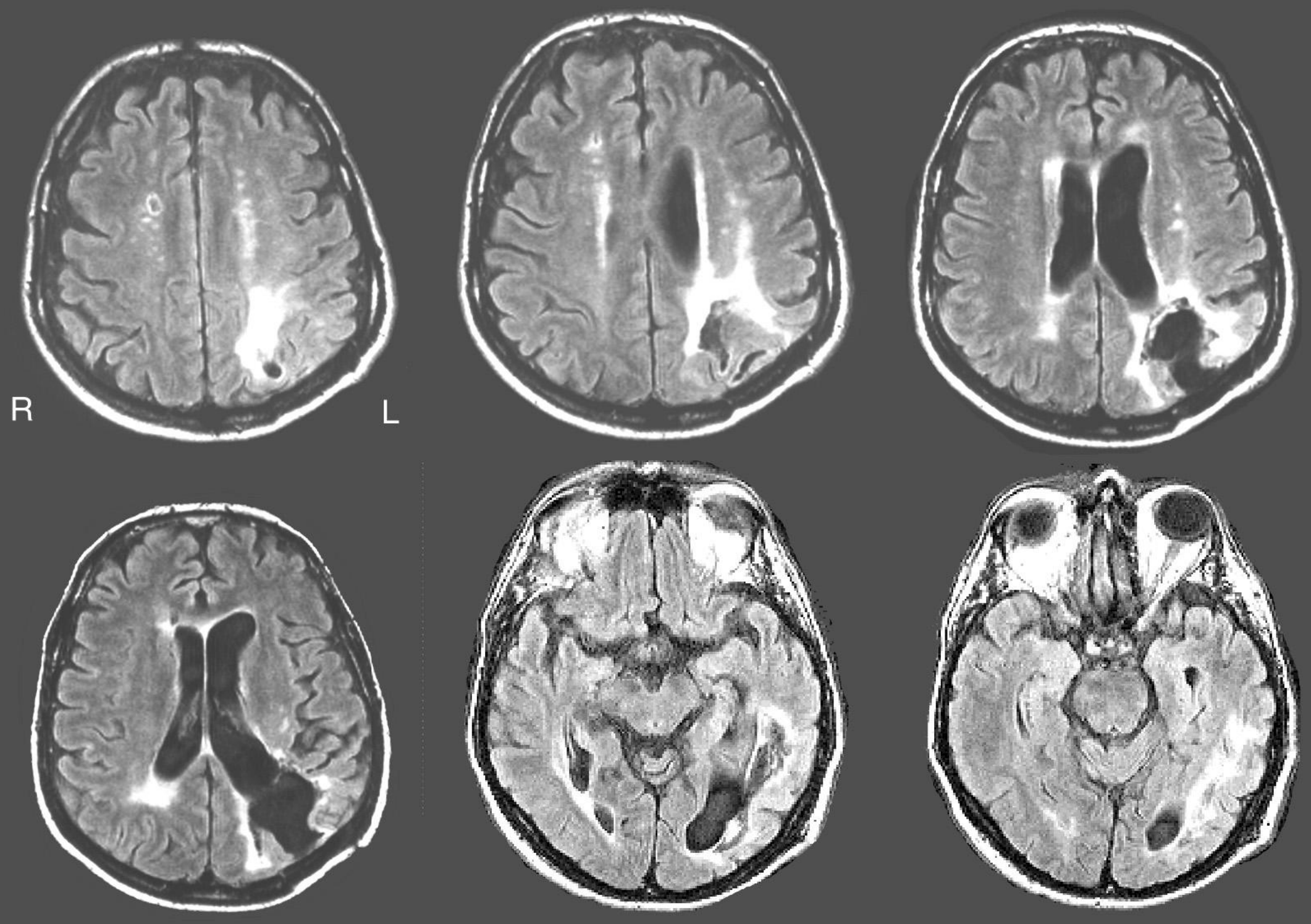


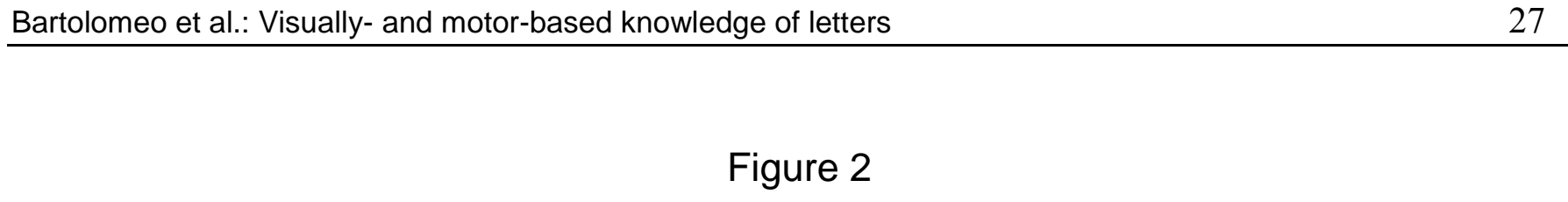

Amour ANIMAL Carlan Activité Ciel. Boite. Hinte lim gass les silanx choutent dan 
Figure 3

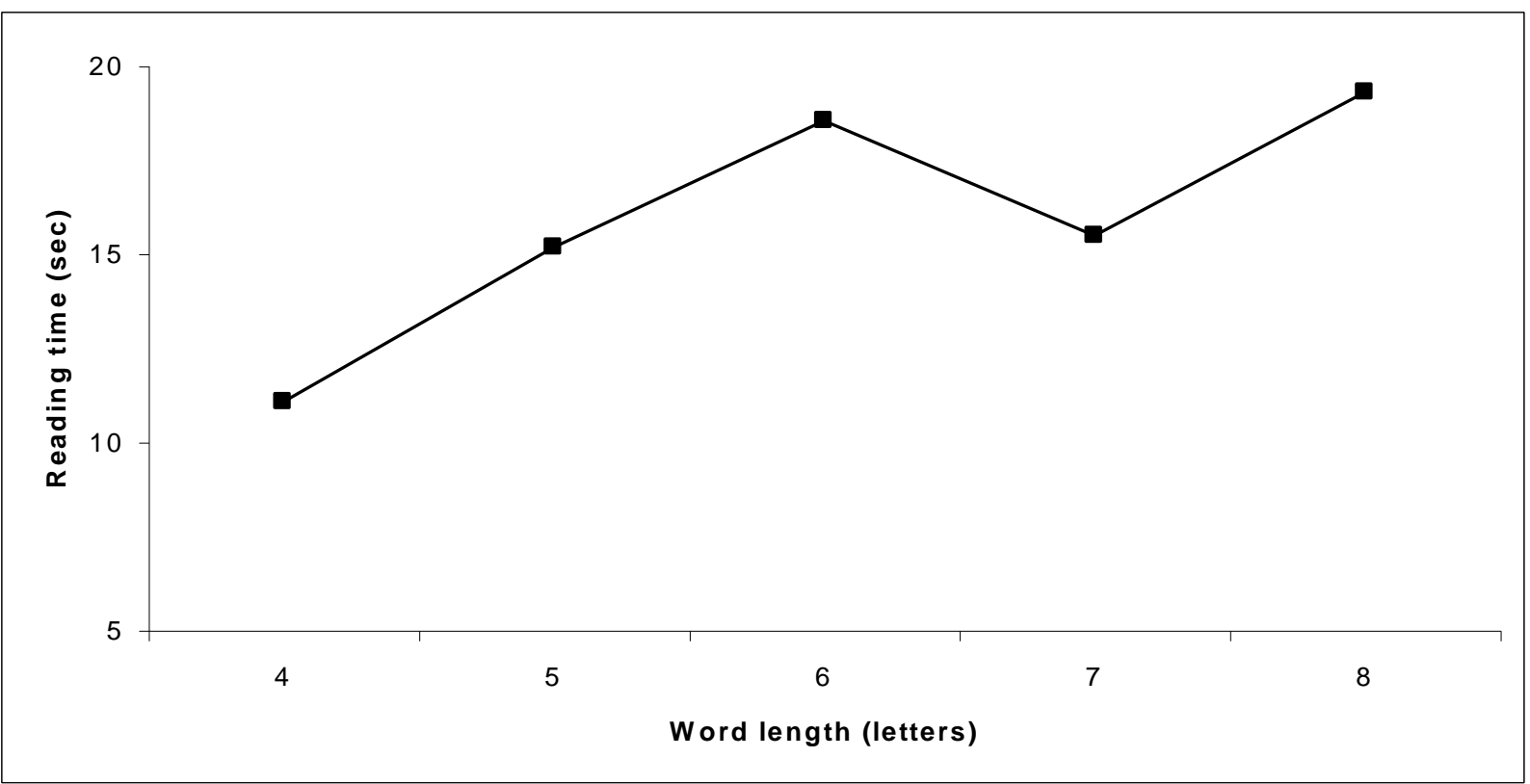

